\title{
Promoting beliefs in the inalienability of human rights by attributing uniquely human emotions through multiple categorization
}

Flavia Albarello, Richard Crisp \& Monica Rubini

To cite this article: Flavia Albarello, Richard Crisp \& Monica Rubini (2018) Promoting beliefs in the inalienability of human rights by attributing uniquely human emotions through multiple categorization, The Journal of Social Psychology, 158:3, 309-321, DOI: 10.1080/00224545.2017.1346581

To link to this article: https://doi.org/10.1080/00224545.2017.1346581

Accepted author version posted online: 28 Jun 2017. Published online: 05 Sep 2017.

Submit your article to this journal $₫$

Llll Article views: 79

Q View related articles ¿

View Crossmark data \lceil

Citing articles: 2 View citing articles 


\title{
Promoting beliefs in the inalienability of human rights by attributing uniquely human emotions through multiple categorization
}

\author{
Flavia Albarello ${ }^{a}$, Richard Crisp ${ }^{b}$, and Monica Rubini ${ }^{c}$ \\ aUniversita degli Studi di Bologna; ${ }^{b}$ Aston Business School; 'University of Bologna
}

\begin{abstract}
The combination of multiple categorization (i.e., the use of multiple criteria to define others) and human identity - the superordinate group of human beings-has recently been highlighted as a method to reduce implicit (i.e., attribution of secondary emotions) and explicit (i.e., attribution of human rights) dehumanization toward Blacks.

In two studies aimed to replicate such evidence the mediating role of secondary emotions in explaining the impact of multiple and human categorization in reducing dehumanization was assessed. The role of implicit cognition, such as attribution of secondary emotions in leading people to attribute human rights to minorities, is discussed.
\end{abstract}

\section{ARTICLE HISTORY}

Received 6 October 2016

Accepted 25 May 2017

Revised 24 May 2017

\section{KEYWORDS}

Dehumanization; human rights; multiple categorizations; racial prejudice; secondary emotions

Racial prejudice is very persistent, even in contemporary multicultural societies that are rooted in democratic principles and condemn any form of prejudice and social discrimination. Not only are Black people still the targets of old-fashioned blatant prejudice (Dovidio \& Gaertner, 2004), but they are also victims of heinous forms of discrimination, such as denial of full humanness to others-i.e. dehumanization (for review, Haslam \& Loughnan, 2014; see also Goff, Eberhardt, Williams, \& Jackson, 2008; Goff, Jackson, Di Leone, Culotta, \& DiTomasso, 2014).

Recently, Albarello and Rubini (2012) highlighted the conditions under which dehumanizing prejudice toward Black people can be successfully ameliorated. They showed that the optimal intervention strategy for reducing dehumanizing prejudice toward Blacks used a combination of multiple categorization (i.e., the use of multiple criteria to categorize others; Crisp \& Hewstone, 2007) and salience of human identity as a means to include outgroupers within a common ingroup of human beings (Gaertner \& Dovidio, 2000).

Given the importance of providing replications of previous findings in order to establish the robustness of gathered evidence (Funder et al., 2014; Schmidt, 2009), this contribution aimed to replicate the evidence by Albarello and Rubini (2012) that multiple and human categorization forms the most efficient social cognitive intervention for reducing dehumanization. Secondly, it aimed to address the possible mediating role of implicit social cognition on others' humanness, such as attribution of secondary emotions (Leyens et al., 2000, 2003) to the target group of Black people on the explicit acknowledgment of human rights (Albarello \& Rubini, 2012) to Blacks.

\section{Infra/dehumanization}

Leyens et al. (2000) highlighted an infrahumanization bias as the tendency to attribute secondary emotions (Ekman, 1992) to ingroupers to a greater extent than outgroupers (for review, see 
Demoulin, Rodriguez-Torres, et al., 2004). Secondary emotions can be considered uniquely human characteristics because they represent a cultural product of civilization processes (Demoulin, Rodriguez-Torres, et al., 2004; Leyens et al., 2000). In this vein, they form emotional experiences that are unique to humans (e.g., resentment, admiration, melancholy, hope). In contrast, primary emotions such as fear or pleasure are believed to be shared with animals and are biologically based (Kemper, 1987).

Interestingly, if this is the distinction between secondary and primary emotions, individuals are not generally aware of attributing emotions which vary in their human content. In this vein, Demoulin, Leyens, et al., (2004) have argued that attribution of secondary emotions can be regarded as an implicit measure of infrahumanization (see also Leyens, Demoulin, Vaes, Gaunt, \& Paladino, 2007) since group members are motivated to provide ingroup/outgroup differentiation but are not aware of doing it by attributing secondary emotions to a varying extent (Leyens et al., 2003).

More recently, Haslam (2006) developed an integrated dual model of dehumanization contending that dehumanization results from both denial of uniquely human (UH) characteristics (e.g., secondary emotions) and human nature (HN; i.e., what is intrinsically human and central to humans). Recent studies highlighted another specific form of dehumanization consisting of denial of mind/dementalization (Waytz, Gray, Epley, \& Wegner, 2010). This process too has been conceptualized as two-fold-i.e., Waytz and colleagues contended that dementalization can derive from denial of agency (i.e., the perceived capacity to act) and denial of experience (i.e., the perceived capacity for sensation and feeling). These two forms of dementalization lead respectively to distinguishing humans from animals, and humans from robots.

In the last two decades, many scholars have addressed infrahumanization and dehumanization as aggravated forms of social prejudice leading one to perceive others as less human than oneself or one's ingroup (e.g., Albarello \& Rubini, 2015; Haslam, Bain, Douge, Lee, \& Bastian, 2005; see also Haslam \& Loughnan, 2014; Haslam, Loughnan, Kashima, \& Bain, 2008; Vaes, Leyens, Paladino, \& Miranda, 2012). Very important for the purpose of our studies is the work of Goff et al. (2008) who tackled the issue of dehumanizing racial prejudice in terms of implicit or explicit activation of the metaphor linking Black people to apes. These authors showed that the implicit activation of the Black-ape metaphor altered participants' judgements about violence against Black people, leading them to condone police violence toward a Black suspect (see also Goff et al., 2014). They also showed that explicit activation of this metaphor in press reports of trials was correlated to assignment to death penalty. Such evidence on the consequences of implicit and explicit dehumanization suggests the importance of developing tools aimed to reduce dehumanization outcomes.

\section{Social categorization and dehumanization}

It is a well-established finding that dichotomous ingroup-outgroup categorization may be sufficient to produce intergroup discrimination (Tajfel, Billig, Bundy, \& Flament, 1971). If categorization provides the basis for intergroup differentiation, it follows that reducing the salience of intergroup distinctions may reduce bias. Recent research (Crisp, Hewstone, \& Rubin, 2001; Crisp \& Hewstone, 2007; Prati, Crisp, Meleady, \& Rubini, 2016) suggests that when perceivers process more than four categorical dimensions defining others, category-oriented processes no longer provide an efficient or meaningful way of making judgments, which leads to blurring intergroup boundaries and reduced intergroup discrimination. This means of definition of others is called multiple categorization (Crisp et al., 2001) and leads to individualization of outgroup members and decreased social prejudice.

Another strategy meant to reduce intergroup prejudice is the common ingroup identity model (Gaertner \& Dovidio, 2000) which-unlike multiple categorization-uses a superordinate means of social categorization leading to recategorization of former ingroupers and outgroupers (see also Gaunt, 2009) in order to extend the cognitive, motivational, and behavioral consequences (e.g., stereotyping, helping) of ingroup membership to former outgroupers. However, maintenance of both subordinate identity and superordinate identity, i.e. dual identity (González \& Brown, 2003), can have multiple contrasting effects. It can lead to enhanced outgroup 
discrimination (Hornsey \& Hogg, 2000), but it can also be considered a successful social integration strategy of minority groups into larger societies (González \& Brown, 2003).

Other studies have considered the role of superordinate human identity (Turner, Hogg, Oakes, Reicher, \& Wetherell, 1987) on intergroup relations. Evidence on the role of this social definition is not conclusive. Although Wohl and Branscombe (2005) showed that priming human identity reduced collective guilt assignment for perpetrators' harm-doing to a larger extent than did social identity salience, Morton and Postmes (2011) showed that perceiving shared humanity with others increased moral defense for the perpetrated harm (for similar evidence see also Greenaway \& Louis, 2010; Greenaway, Quinn, \& Louis, 2011).

In the light of these notions, Albarello and Rubini (2012), reasoning in terms of "an increase of optimizing factors in derailing dehumanization" (p. 876), hypothesized that multiple categorization and human identity could form an optimizing factor in reducing dehumanization, also given the lack of studies addressing interventions to reduce this heinous form of prejudice. In their research, they contrasted five experimental conditions (i.e., simple White categorization, simple Black categorization, multiple Black categorization, simple and human Black categorization, multiple and human Black categorization). Results showed that in the simple categorization condition, the Black target was dehumanized to a higher extent than the White one. Interestingly, dehumanization was lower in the multiple than simple categorization condition. The optimal condition for the reduction of dehumanization was multiple and human categorization condition. Such evidence is particularly striking since it was the first time that multiple and human categorization was highlighted as an intervention for reducing dehumanization. In this vein, it would be important to collect further evidence contributing to strengthen the robustness of its effect in hindering dehumanization.

\section{The current research}

Following the call to improve "dependability" of research in social psychology (Funder et al., 2014), the main goal of these studies was to replicate evidence on the role of multiple and human categorization on reduction of dehumanization (Albarello \& Rubini, 2012). The studies also tested the possible mediating role of attribution of secondary emotions as an implicit means of intergroup differentiation (Leyens et al., 2003) in explaining the effects of multiple and human categorization on the attribution of human rights to the minority group of Blacks. Human rights are an explicit means of (de)humanization in the sense that participants read the statements relating to the human right at stake and assess the extent to which the right has to be acknowledged to the target group (cf. Albarello \& Rubini, 2012).

The rationale for hypothesizing a link between the implicit attribution of secondary emotions and the explicit acknowledgment of human rights derives from Gawronski and Bodenhausen's (2006) contention. These authors have distinguished between associative versus propositional processes. Implicit cognition, such as attributing secondary emotions to a target group, is based on associative processes linking the group to a characteristic, which, in this case, is related to reduced humanness (i.e., Blacks are less human than Whites; Goff et al., 2008; see also Demoulin, Rodriguez-Torres, et al., 2004; Leyens et al., 2003). This can be conceived as an automatic affective reaction activated when one encounters the relevant stimulus and does not require much cognitive capacity or intentional information processing to evaluate the target (Gawronski \& Bodenhausen, 2006). In contrast, propositional processes are based on syllogistic, interrelated cognitions, reciprocally linked to each other, which lead to the formation of a mindful judgement on the target. In this vein, perceivers are first exposed to the target group, then to the socio-cognitive goal of evaluating the extent to which a certain statement applies to the group and on this basis they formulate their judgement (Gawronski \& Bodenhausen, 2006). In this vein, rating the extent to which a human right is applicable to Blacks forms an explicit judgement on their perceived humanity.

Gawronski and Bodenhausen (2006) contended that explicit cognition can be transformed by changes in implicit cognition (for example, we can think of changes in gender stereotypes as 
mediated by a change in the colors of clothes of male and females babies). Following this line of reasoning in these studies we assessed the mediational role of attribution of secondary emotions on attribution of human rights to Blacks.

To the end of replicating previous findings of Albarello and Rubini (2012), Study 1 contrasted a simple categorization condition to both a multiple categorization condition and a multiple and human categorization condition, since these latter ones were the most effective conditions for detecting reduction of dehumanization toward a Black target in the work of Albarello and Rubini (2012). Study 2 contrasted simple categorization to multiple and human categorization.

\section{Study 1 \\ Method}

\section{Participants}

Eighty-three White Italian undergraduate students without immigrant background participated in the study on a voluntary basis $\left(M_{\text {age }}=22.51, S D=3.54\right.$; females $\left.=60.2 \%\right)$. Participants were randomly assigned as follows in the three experimental conditions: $n$ simple categorization $=26 ; n$ multiple categorization $=25 ; n$ multiple and human categorization $=26$.

\section{Procedure and materials}

Participants completed a paper-and-pencil questionnaire. They received a description of a target person manipulating the experimental conditions as in Albarello and Rubini's (2012) study. Participants read the information that: "During recent decades, the social milieu of the country has changed as a consequence of immigration flows. What follows is a description of a person, which you will have to read carefully and keep in mind while answering the following questions." In the simple categorization condition, the target was described only on the basis of skin color (i.e., "a Black person"). In the multiple categorization condition, the target was presented as "a Black, Christian, male, young person, who was born in Italy from immigrant parents." In the multiple and human categorization condition, after reading the aforementioned description of the target, human identity was primed by asking participants to fill in a scale of identification with the human group. In the simple categorization condition, participants completed this scale after assessment of all dependent measures. At the end of the questionnaire, participants also reported their personal data and their religious orientation ${ }^{1}$.

Human identity prime manipulation. As in Albarello and Rubini (2012), human identity was primed by asking participants to answer $(1=$ not at all; $7=$ very $m u c h)$ to a 4 -item human identification scale ( $\alpha=.77$; "I identify with all human beings"; "I feel strong connections with all human beings"; "I am like all human beings, irrespectively of ethnic, political, religious, social or ideological differences"; "I am proud to belong to the humankind").

In the current study, like in Albarello and Rubini (2012), the order of presentation of the human identification scale did not produce any significant effect across conditions, $F(80)=0.42, p=.659, \eta^{2}=.010$. Scores of this scale were thus not considered in subsequent data analyses.

Pre-testing multiple and human categorization manipulation. A pre-test was run $(N=23$ undergraduate students; $M_{\text {age }}=22.00, S D=1.45$; females $=65.2 \%$ ) to examine if each categorical dimension included in multiple and human categorization manipulation was perceived as equally important in describing the target. This was done to ensure that multiple categories have the same impact on the reduction of dehumanization. In specific terms, participants rated on 7-point scales ( $1=$ not at all; $7=$ very $m u c h$ ) the extent to which their impression was affected by the information "he is Black" (item1), "he is Christian" (item2), "he is a male" (item3), "he is young" (item4), "he was born in Italy from immigrant parents" (item5), and "he is a human being" (item6). The repeated-measures Analysis of 
Table 1. Human rights full statements.

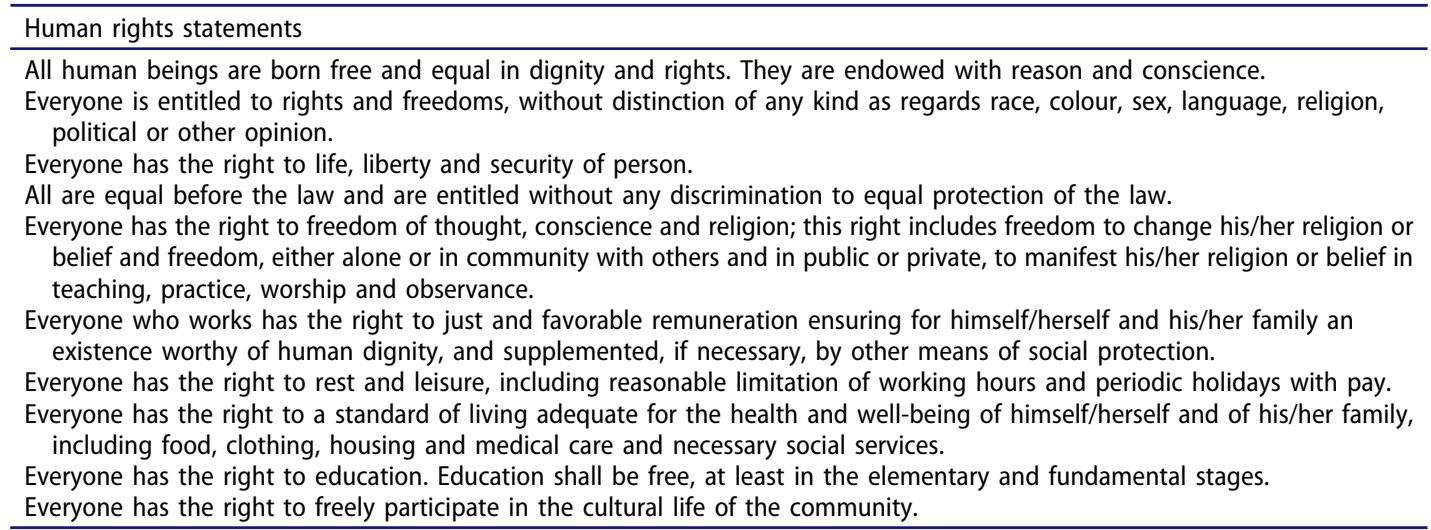

Variance (ANOVA) conducted on the scores of these items revealed no differences $\left(M_{\text {item } 1}=4.65\right.$, $S D=1.43 ; M_{\text {item2 }}=4.17, S D=1.92 ; M_{\text {item } 3}=3.87, S D=1.49 ; M_{\text {item4 }}=4.09, S D=1.93 ; M_{\text {item } 5}=4.00$, $\left.S D=2.02 ; M_{\text {item6 }}=4.04, S D=1.43\right), F(5,18)=0.70, p=.629, \eta^{2}=.163$. All pairwise comparisons (Least Significance Differences test) were not significant, $p s \leq .134$.

\section{Dependent variables}

Attribution of secondary emotions. Participants attributed to the target $(1=$ not at all; $7=$ very much) the secondary emotions employed by Albarello and Rubini (2012). These emotional experiences consisted of three positive secondary emotions (i.e., hope, admiration, optimism) and three negative secondary emotions (i.e., pessimism, regret, remorse). The order of the emotions was randomized. As in Albarello and Rubini (2012), ratings of positive and negative secondary emotions were averaged to form a single mean score $(\alpha=.84)$ since they do not differ in humanity (Leyens et al., 2000).

Attribution of human rights. Participants were presented with the list (see Table 1) of 10 statements taken from the Universal Declaration of Human Rights previously employed by Albarello and Rubini (2012). Participants rated inalienability to the Black target of each right described in the statements $(1=$ not at all; $7=$ very $m u c h)$. A mean score expressing attribution of human rights to the target $(\alpha=.96)$ was computed.

Importantly, participants also rated the extent to which each right captured a fundamental dimension of humanness $(1=$ not at all; $7=$ very $m u c h)$. The humanity scores of each right were higher than the mid-point of the scale (Ms $\geq 6.16), t s(82) \geq 15.80$, $p s<.001$.

\section{Results and discussion}

\section{Attribution of secondary emotions and of human rights}

The one-way ANOVA (target condition: simple categorization, multiple categorization, multiple and human categorization) on the mean score of secondary emotions showed that attribution of secondary emotions varied as a function of target condition $\left(M_{\text {simple categorization }}=4.04, S D=0.72\right.$; $M_{\text {multiple categorization }}=4.73, S D=0.69 ; M$ multiple and human categorization $=5.67, S D=0.64$ ), $F(80)=42.09, p<.001, \eta^{2}=.513$. Pairwise comparisons showed that all conditions significantly differed one from another $(p s \leq .001)$. Importantly, multiple and human categorization led to attribution of secondary emotions to the target to a higher extent than multiple categorization alone. 
The ANOVA on attribution of human rights revealed a significant effect of target condition $\left(M_{\text {simple categorization }}=5.41, S D=1.17 ; M\right.$ multiple categorization $=5.93, S D=0.89 ; M$ multiple and human categorization $=6.55, S D=0.74), F(80)=10.96, p<.001, \eta^{2}=.215$. In line with expectations, multiple and multiple and human categorization led to reduction of dehumanization in comparison to simple categorization $(p s \leq .050)$. In the multiple and human categorization condition, human rights were higher than in the multiple categorization one $(p=.013)$. Pearsons' Correlations $(N=83)$ highlighted that secondary emotions and human rights were correlated $(r=.611, p<.001)$. Importantly, as shown by a series of ANOVAs, attribution of secondary emotions and attribution of human rights were not affected by participants' gender (male, female), nor participant's religious orientation (not religious, Christian), respectively, $F s \leq 0.41, p s \geq .525$, and, $F s \leq 1.03, p s \geq .313$.

\section{Mediational analysis}

To address the second aim of this contribution, bootstrapping mediational analysis $(5,000$ re-samples) was conducted using the methods described by Hayes and Preacher (2014) for mediational models employing multicategorical independent variables. The independent variable was recoded in two dummy variables: $\mathrm{D}_{1}$ contrasted the simple categorization (coded 0 ) and multiple categorization (coded 1) conditions; $\mathrm{D}_{2}$ compared the simple categorization (coded 0 ) and the multiple and human categorization (coded 1) conditions. $\mathrm{D}_{1}$ and $\mathrm{D}_{2}$ were entered simultaneously as independent variables in the regression model. The PROCESS 2.15 macro for SPSS (model 4) was employed, since it produces omnibus tests of total, direct, and indirect effects indicating whether there is an effect of the independent variables on the outcome variable without specifying which dummy variable is responsible for the effect. First of all, both $\mathrm{D}_{1}$ $(B=0.69, S E=0.19)$ and $\mathrm{D}_{2}(B=1.62, S E=0.18)$ significantly affected the mediator (i.e., attribution of secondary emotions), $p s<.001$. The omnibus test of total effects of the two dummy variables was significant, $F(2,80)=10.96, p<.001$. As shown in Table 2 , the total effects of $D_{1}$ and $D_{2}$ were both significant. When the mediator was included in the model, the omnibus test of direct effects of $\mathrm{D}_{1}$ and $\mathrm{D}_{2}$ was not significant, $F(2,79)=0.10, p=.904$. The relative direct effects of $\mathrm{D}_{1}$ and $\mathrm{D}_{2}$ on the dependent variable turned to non-significance. The omnibus test of indirect effects through the mediator was significant, since the $95 \%$ Confidence Interval (CI) $[0.15,0.54]$ did not include zero. Also the specific indirect effects of $\mathrm{D}_{1}$ and $\mathrm{D}_{2}$ through the mediators were significant, respectively $[0.17,0.81]$ and $[0.52,1.68]$. Overall, these

Table 2. Total, direct, and indirect effects of predictors of attribution of human rights to the target (Study 1).

\begin{tabular}{|c|c|c|c|c|c|c|c|c|c|c|}
\hline \multirow[b]{2}{*}{ Predictor } & \multicolumn{3}{|c|}{ Total effect } & \multicolumn{3}{|c|}{ Direct effect } & \multicolumn{4}{|c|}{ Total Indirect effect $95 \% \mathrm{Cl}$} \\
\hline & B & SE & $p$ & B & $S E$ & $p$ & B & $S E$ & $L L$ & $U L$ \\
\hline $\mathrm{D}_{1}$ & 0.69 & 0.19 & .000 & 0.09 & 0.25 & .716 & 0.42 & 0.28 & 0.17 & 0.81 \\
\hline$D_{2}$ & 1.62 & 0.18 & .000 & 0.14 & 0.31 & .668 & 1.01 & 0.29 & 0.52 & 1.67 \\
\hline
\end{tabular}

Note: $\mathrm{D}_{1}=$ simple categorization (0), multiple categorization (1); $\mathrm{D}_{2}=$ simple categorization (0), multiple and human categorization (1); $\mathrm{Cl}=$ confidence interval; $L L=$ lower limit; $U L=$ upper limit.

Table 3. Conditional direct and indirect effects of predictors of attribution of human rights to the target at different values of perceived similarity (Study 2).

\begin{tabular}{|c|c|c|c|c|c|c|c|c|}
\hline \multirow[b]{2}{*}{ Predictor } & \multicolumn{4}{|c|}{ Conditional Direct effect } & \multicolumn{4}{|c|}{ Conditional Indirect effect $95 \% \mathrm{Cl}$} \\
\hline & Similarity & $B$ & SE & $p$ & $B$ & $S E$ & $L L$ & $U L$ \\
\hline \multirow{3}{*}{ Target condition } & Lower similarity & 0.16 & 0.43 & .716 & 0.59 & 0.24 & 0.16 & 1.10 \\
\hline & Mean similarity & 0.13 & 0.31 & .682 & 0.54 & 0.19 & 0.24 & 1.00 \\
\hline & Higher similarity & 0.13 & 0.42 & .810 & 0.50 & 0.30 & 0.02 & 1.20 \\
\hline
\end{tabular}

Note: Target condition ( 0 = simple categorization; 1 = multiple and human categorization); $\mathrm{Cl}=$ confidence interval; $L L=$ lower limit; $U L=$ upper limit. 
results revealed mediation of the effects of multiple and multiple and human categorization on attribution of human rights to the Black target by secondary emotions.

Even though alternative models seemed less plausible, since the literature strongly supports the notion that it is implicit cognition that affects explicit attitudes (Gawronski \& Bodenhausen, 2006), we tested the alternative model of attribution of human rights as the mediator of the effects of multiple and multiple and human categorization on attribution of secondary emotions to the Black target. The omnibus test of the direct effects of the two dummy variables was still significant when the mediator was included in the model, $F(2,79)=24.30, p<.001$. Both the specific direct effects of $\mathrm{D}_{1}$ and $\mathrm{D}_{2}$ were also significant, respectively, $B=0.52, S E=0.18, p=.004$, and, $B=1.24, S E=0.18, p<.001$. The indirect effect of $\mathrm{D}_{1}$ through the mediator, $B=0.52, S E=0.18$, was not significant with the $95 \% \mathrm{CI}[-0.01,0.43]$ including zero. The indirect effect of $\mathrm{D}_{2}$ through the mediator, $B=1.24, S E=0.18$, was significant, since the $95 \%$ CI $[0.16,0.72]$ did not include zero. Also the omnibus indirect effect of the independent variables through the mediator was significant, with the $95 \%$ CI $[0.01,0.15]$ not including zero. Nevertheless, if compared to the results of the hypothesized mediational model, this finding is less strong as shown by the smaller CIs for the omnibus indirect effect and for $\mathrm{D}_{2}$.

Overall, Study 1 contributed to replicating the evidence gathered by Albarello and Rubini (2012), showing again that multiple categorization, and above all, multiple and human categorization are effective interventions to achieve reduction of dehumanization toward Black people, both in terms of implicit and explicit measures of (de)humanization.

Study 1 also provided further advance to the previous evidence by shedding light on the unexplored process underlying the effects of multiple and multiple and human categorization on reduction of dehumanization by mediation of attribution of secondary emotions on human rights.

\section{Study 2}

Considering the evidence of the previous study, one might argue that the effect of multiple and human categorization in leading to reduced dehumanization of the target is due to the fact that participants share at least common human belongingness with the target, which might have enhanced perceived similarity between the target and respondent.

In this vein, it should be stressed that the issue of perceived similarity in multiple categorization interventions has not received adequate attention. This is due to the fact that multiple categorization is believed to impede perception of intracategory similarities and intercategory differences (see Doise, 1978). Multiple categorization effect on prejudice reduction relies on an individuation/ decategorization process (Crisp \& Hewstone, 2007; see also Prati et al., 2016) since, as the number of categorizations increases, it is more difficult for perceivers "to determine on what basis they are similar to, or different from the target person” (Hall \& Crisp, 2005, p. 1436). For this reason, Crisp and Hewstone (2000) suggested analyzing the effects of similarity on multiple group membership shifting emphasis from mediation to moderation. Taking this stance, Study 2 added to the previously tested mediational model the control over the possible moderating role of perceived similarity with the target.

\section{Method}

\section{Participants}

Fifty-nine White Italian undergraduate students, without immigrant background, participated in the study on a voluntary basis $\left(M_{\text {age }}=21.86, S D=4.34\right.$; females $\left.=74.1 \%\right)$. Participants were randomly assigned as follows in the two experimental conditions: $n_{\text {simple categorization }}=28 ; n$ multiple and human categorization $=31$. 


\section{Procedure and materials}

The simple categorization and multiple and human categorization conditions were manipulated as in Study 1. As in Study 1, the variation in the order of presentation of the human identification scale $(\alpha=.73)$ did not affect human identification, $t(57)=-1.51, p=.137, \eta^{2}=.028$. Therefore, human identification was not employed in further analyses.

Participants filled in the secondary emotions $(\alpha=.74)$ and human rights $(\alpha=.94)$ measures employed in Study 1. In order to assess perceived similarity between the target and respondent, participants also rated the extent to which the target "was similar to" (item1) and "was like" (item2) them. The scores of these items were then averaged $(\alpha=.77)^{2}$.

As in Study 1, participants also rated the extent to which each right captured a fundamental dimension of humanness. The humanity scores of each right were higher than the mid-point of the scale $(M s \geq 5.86), t s(58) \geq 9.60$, ps $<.001$. At the end of the questionnaire they reported their personal data and religious orientation.

\section{Results and discussion}

\section{Attribution of secondary emotions and of human rights}

As shown by an independent samples $t$ test (target condition: simple categorization, multiple and human categorization), target condition significantly affected secondary emotions $\left(M_{\text {simple categorization }}=4.26\right.$, $\left.S D=1.12 ; M_{\text {multiple and human categorization }}=5.06, S D=0.73\right), t(57)=-3.29, p=.002, \eta^{2}=.157$. In line with expectations and replicating evidence of Study 1, secondary emotions were attributed to the target to a greater extent in the multiple and human categorization condition than in the simple one. Similarly, as revealed by another $t$ test, human rights were attributed to the Black target to a greater extent in the multiple and human categorization condition than in the simple one $\left(M_{\text {simple categorization }}=4.99, S D=0.83 ; M_{\text {multiple }}\right.$ and human categorization $=5.67, S D=1.51, t(57)=-2.10, p=.040, \eta^{2}=.071$. As shown by Pearsons' Correlations $(N=59)$, attribution of secondary emotions and of human rights were correlated $(r=.551, p<.001)$. Importantly, as shown by a series of independent samples $t$ tests, attribution of secondary emotion and attribution of human rights were not affected by participant's gender (male, female), nor participant's religious orientation (not religious, Christian), respectively, $t \mathrm{~s} \leq-1.49$, $p s \geq .142$, and, $t \mathrm{~s} \leq-0.94, p s \geq .352$.

\section{Mediational analysis}

Bootstrapping mediational analysis (5,000 re-samples) was conducted using the methods described by Hayes (2015) for estimating conditional direct and indirect effects in moderated mediational models. The PROCESS 2.15 macro for SPSS (model 8) was employed, since it allows testing the conditional indirect effects of the independent variable (i.e., target condition) on the dependent variable (i.e., attribution of human rights) through the mediator (i.e., attribution of secondary emotions) at the different levels of the moderator (i.e., perceived similarity with the target). The centered mean score of similarity was entered in the mediational model as moderator. First, the analysis showed that the independent variable (i.e., target condition) significantly affected the mediator (i.e., secondary emotions), $B=0.80, S E=0.24, p=.002$. The moderator (i.e., perceived similarity) had a marginal effect on the mediator, $B=0.31, S E=0.17, p=.075$. The interaction effect of the moderator by the independent variable on secondary emotions was not significant, $B=-0.07, S E=0.24, p=.767$. When the mediator was included in the model, it significantly predicted attribution of human rights, $B=0.68, S E=0.16$, $p<.001$. As shown in Table 3, the conditional direct effect of target condition on the moderator and the interactions of secondary emotions $\times$ similarity and of type of categorization $\times$ similarity were not significant, respectively, $B=0.13, S E=0.31, p=.682 ; B=-0.05, S E=0.21, p=.882$; and, $B=-0.03$, $S E=0.29, p=.925$. The conditional indirect effect of target condition through the mediator at the different values of the moderator was significant as shown by the $95 \%$ CIs for each level of perceived similarity (i.e., lower, mean, higher), which did not include zero, respectively, $B=0.59, S E=0.24$, CI 
$[0.16,1.10] ; B=0.54, S E=0.19$, CI $[0.23,1.01] ; B=0.50, S E=0.30$, CI $[0.02,1.20]$, whereas the index of moderated mediation was not significant, $B=-0.05$, $S E=0.19$, CI $[-0.39,0.37]$. These findings reveal that attribution of secondary emotions significantly mediated the effects of multiple and human categorization on attribution of human rights to the Black target at each level of perceived similarity and that perceived similarity did not moderate the significant mediating effect of attribution of secondary emotions on attribution of human rights.

Importantly, a further bootstrapping mediational analysis (5,000 re-samples) was conducted to test the alternative model entering attribution of human rights as the mediator of the effect of target condition on attribution of secondary emotions towards the target and perceived similarity as the moderating variable. This analysis was conducted employing the PROCESS 2.15 (model 8) MACRO for SPSS and showed that the conditional indirect effects of the independent variable through the mediator were not significant at each of the different levels of the moderator, as shown by the $95 \%$ CIs including zero (respectively, for lower similarity [-0.05, 0.87]; for mean similarity [-0.00, 0.84]; for higher similarity $[-0.17,1.00])$. Also the index of moderated mediation was not significant, $B=-0.03, S E=0.16$, CI $[-0.40,0.26]$.

Overall, evidence of Study 2 confirmed the effectiveness of multiple and human categorization as a factor reducing dehumanization toward Blacks. It also replicated evidence of Study 1 showing that the effect of multiple and human categorization in leading to greater attribution of human rights to the Black target is mediated by attribution of secondary emotions. Beyond replication purposes, this evidence contributed to ruling out the alternative explanation of the moderating role of perceived similarity with the target. Importantly, perceived similarity did not vary as a function of target condition (cf. Note 2). Moreover, the moderated mediational analysis also showed that perceived similarity between target and respondent did not account for differences in the attribution of humanness to the target nor affected the expected mediational effect of secondary emotions on human rights. Overall, this study confirmed what has only been argued by multiple categorization scholars, i.e. the fact that increasing the numbers of categories defining others makes it difficult to establish on what basis they are similar or dissimilar to oneself (Hall \& Crisp, 2005).

\section{General discussion}

This set of studies provided evidence on the robustness of multiple and, especially, multiple and human categorization (Albarello \& Rubini, 2012) as effective interventions to reduce dehumanizing prejudice toward Blacks. In view of recommendation of scientific community (e.g., Funder et al., 2014), such replication of previous findings might be regarded as remarkable and very welcomed.

Besides this, the current studies also tackled for the first time the process that might explain the effects of multiple and human categorization on explicit attribution of human rights to Blacks. Specifically, the attribution of secondary emotions (Leyens et al., 2000) mediated the positive impact of multiple and human categorization on attribution of human rights to a Black target in both studies. Such evidence was replicated in Study 2 controlling for moderation by perceived similarity between the target and participant. In this vein, this study also added to the work on multiple categorization (Prati et al., 2016) by directly addressing for the first time perceived similarity with the target as a potential moderator of the effect of multiple and human categorization.

\section{Theoretical implications}

While previous studies have shown that people tend to consider outgroup members as endowed with lesser humanity (Vaes et al., 2012), findings of this contribution consistently highlight that by processing multiple categorical information (Albarello \& Rubini, 2015; Crisp \& Hewstone, 2007; Fiske, 2015; Kang \& Bodenhausen, 2014) the perception of outgroupers' humanity is enhanced at the implicit level of attribution of uniquely human emotions and, in turn, at the explicit level of attribution of human rights. 
In this vein, if Goff et al. $(2008,2014)$ have stressed the heinous side of implicit cognition by highlighting the negative role of the Black-ape metaphor, these studies were able to show the beneficial role that implicit associative cognition on Blacks' humanness can have on explicit, propositional, attribution of human rights to them, thus leading to reduction of overt dehumanization outcomes such as the denial of human rights to minorities.

\section{Practical implications and applications}

These studies suggest some important guidance for dealing with diversity in multicultural societies and give suggestions for setting effective means to reduce prejudice and dehumanization. They show how multiple categorization, as a social-cognitive resource, can lead to better intergroup relations by promoting "coalition building" between various groups (Albarello \& Rubini, 2012; Crisp \& Meleady, 2012).

In this vein, the evidence of these studies is absolutely in line with Fiske's (2015) agenda stressing multiple categorization as one of the crucial social cognitive means through which social psychology can help addressing the issues raised by hybrid and poly-cultural societies in our changing world. This might not be necessarily only related to Black people but also to other minority or ethnic groups toward whom people hold dehumanizing prejudice (e.g., Roma; Muslims). In other words, the current approach could be extended to other social contexts as an initial intervention to improve intergroup relations: By challenging dichotomous ingroup versus outgroup representations through multiple categorization, outgroupers come to be seen as more human.

In this vein, educational policies can be particularly important in countermanding chronically accessible tendencies to perceive one's own and other groups in terms of exclusive categorizations. These findings suggest that children should be educated to think in multiple categorical terms from the very beginning of their school experience (Bigler \& Liben, 2007). This may lead to a more inclusive representation of contemporary societies in which human rights are acknowledged to a higher extent to everybody because outgroups are perceived as equally human at implicit levels.

\section{Limitations and future directions}

Further research should test the mediational hypothesis employing other manipulations of multiple categorization as well as salience of human identity. Given that our mediational analyses were performed on cross-sectional data, future studies should also employ a longitudinal design to assess more certainly the influence of attribution of secondary emotions on attribution of human rights to the target. Future work should also employ implicit techniques (Greenwald \& Banaji, 1995) to assess dehumanization and provide further tests of the role of implicit evaluations of others' humanity on explicit, more controllable measures of dehumanization. Future research should also consider other forms of dehumanization, besides attribution of uniquely human characteristics such as secondary emotions, as we did in this contribution. Besides this, given the growing interest of social psychologists in developing measures of global human identification and assessing its relation with humanitarian concerns (e.g., McFarland, Brown, \& Webb, 2013; McFarland \& Hornsby, 2015), future work should assess the moderating role of an individual's human identification in reducing prejudice and dehumanization towards stigmatized social groups besides operationalizing it as a prime of the human level of self-categorization as in our studies and in Albarello and Rubini (2012).

Another interesting issue to address is related to human rights and how they are related to the existing models of dehumanization (e.g., Haslam, 2006). In this contribution, we did not control whether human rights imply $\mathrm{HN}$ or $\mathrm{UH}$ characteristics. However, participants rated for each right the extent to which it captured fundamental human characteristics. Future studies might address this issue more closely. Moreover, drawing on evidence showing that lack of human nature and experience (i.e., moral patiency; see Gray \& Wegner, 2009) is associated with reduced moral worth 
(Haslam \& Loughnan, 2014) future studies should consider whether these factors are also important to ascription of human rights.

In sum, deepening the processes underlying attribution of human rights to stigmatized groups is crucial, since such pivotal principles of democratic societies reveal, as a thermometer, the extent to which social groups are excluded or can be integrated by society.

Thus, the strategies leading to acknowledgment of others' humanity, such as the ones highlighted in this contribution, might be at the basis of social change and help political management of contemporary multicultural societies, thus leading to promotion of more harmonious intergroup relations.

\section{Notes}

1. Participants chose among different provided alternatives (i.e., atheist, agnostic, culturally Christian, Christian, Catholic, observant Catholic). Answers were recoded into a dummy variable $(0=$ not religious; $1=$ Christian $)$ such that the "atheist" and "agnostic" options fell into the "not religious category" and the others into the "Christian category."

2. As shown by an independent samples $t$ test (target condition: simple categorization, multiple and human categorization), perceived similarity between the target and respondent did not vary as a function of target condition $\left(M_{\text {simple categorization }}=4.66, S D=1.31 ; M_{\text {multiple and human categorization }}=4.70, S D=1.24\right), t(57)=-0.11$, $p=.916, \eta^{2}=.157$.

\section{References}

Albarello, F., \& Rubini, M. (2012). Reducing dehumanization outcomes towards Blacks: The role of multiple categorization and of human identity. European Journal of Social Psychology, 42, 875-882. doi:10.1002/ ejsp.1902

Albarello, F., \& Rubini, M. (2015). The role of reduced humanity in producing linguistic discrimination. Personality and Social Psychology Bulletin, 41, 224-236. doi:10.1177/0146167214561195

Bigler, R. S., \& Liben, L. S. (2007). Developmental intergroup theory: Explaining and reducing children's social stereotyping and prejudice. Current Directions in Psychological Science, 16, 162-166. doi:10.1111/j.14678721.2007.00496.x

Crisp, R. J., \& Hewstone, M. (2000). Multiple categorization and social identity. In D. Capozza, \& R. J. Brown (Eds.), Social identity processes: Trends in theory and research (pp. 149-166). London, UK: Sage Publications.

Crisp, R. J., \& Hewstone, M. (2007). Multiple social categorization. In M. P. Zanna (Ed.), Advances in experimental social psychology (Vol. 39, pp. 163-254). San Diego, CA: Academic Press. doi:10.1016/S0065-2601(06)39004-1

Crisp, R. J., Hewstone, M., \& Rubin, M. (2001). Does multiple categorization reduce intergroup bias? Personality and Social Psychology Bulletin, 27, 76-89. doi:10.1177/0256167201271007

Crisp, R. J., \& Meleady, R. (2012). Adapting to a multicultural future. Science, 336, 853-855. doi:10.1126/ science. 1219009

Demoulin, S., Leyens, J. P., Paladino, P. M., Rodríguez, A. P., Rodríguez, R. T., \& Dovidio, J. (2004). Dimensions of "uniquely" and "non uniquely" human emotions. Cognition and Emotion, 18, 71-96. doi:10.1080/ 02699930244000444

Demoulin, S., Rodríguez, R. T., Rodríguez, A. P., Vaes, J., Paladino, M. P., Gaunt, R., ... Leyens, J. P. (2004). Emotional prejudice can lead to infra-humanization. In W. Stroebe, \& M. Hewstone (Eds.), European review of social psychology (Vol. 15, pp. 259-269). London, UK: Psychology Press. doi:10.1080/10463280440000044

Doise, W. (1978). Groups and individuals. Explanations in social psychology. Cambridge, UK: Cambridge University Press.

Dovidio, J. F., \& Gaertner, S. L. (2004). Aversive racism. In M. P. Zanna (Ed.), Advances in experimental social psychology (Vol. 36, pp. 1-51). doi:10.1016/S0065-2601(04)36001-6

Ekman, P. (1992). An argument for basic emotions. Cognition and Emotions, 6, 169-200. doi:10.1080/ 02699939208411068

Fiske, S. (2015). Grolar bears, social class, and policy relevance: Extraordinary agendas for the emerging 21 st century. European Journal of Social Psychology, 45, 551-559. doi:10.1002/ejsp.2117

Funder, D. C., Levine, J. M., Mackie, D. M., Morf, C. C., Sansone, C., Vazine, S., \& West, S. G. (2014). Improving dependability of research in personality and social psychology: Recommendations for research and educational practice. Personality and Social Psychology Review, 18, 3-12. doi:10.1177/1088868313507536 
Gaertner, S. L., \& Dovidio, J. F. (2000). Reducing intergroup bias: The common ingroup identity model. Philadelphia, PA: Psychology Press.

Gaunt, R. (2009). Superordinate categorization as a moderator of mutual infrahumanization. Group Processes \& Intergroup Relations, 12, 731-746. doi:10.1177/1368430209343297

Gawronski, B., \& Bodenhausen, G. V. (2006). Associative and propositional processes in evaluation: An integrative review of implicit and explicit attitude change. Psychological Bulletin, 132, 692-731. doi:10.1037/00332909.132.5.692

Goff, P. A., Eberhardt, J. L., Williams, M. J., \& Jackson, M. C. (2008). Not yet human: Implicit knowledge, historical dehumanization, and contemporary consequences. Journal of Personality and Social Psychology, 94, $292-306$. doi:10.1037/0022-3514.94.2.292

Goff, P. A., Jackson, M. C., Di Leone, B. A. L., Culotta, C. M., \& DiTomasso, N. A. (2014). The essence of innocence: Consequences of dehumanizing Black children. Journal of Personality and Social Psychology, 106, 526-545. doi: $10.1037 / \mathrm{a} 0035663$

González, R., \& Brown, R. (2003). Generalization of positive attitudes as a function of subgroup and superordinate group identifications in intergroup contact. European Journal of Social Psychology, 33, 195-214. doi:10.1002/ ejsp. 140

Gray, K., \& Wegner, D. M. (2009). Moral typecasting: Divergent perceptions of moral agents and moral patients. Journal of Personality and Social Psychology, 96, 505-520. doi:10.1037/a0013748

Greenaway, K. H., \& Louis, W. R. (2010). Only human: Hostile human norms can reduce legitimization of intergroup discrimination by perpetrators of historical atrocities. British Journal of Social Psychology, 49, 765-783. doi:10.1348/ 014466609X479202

Greenaway, K. H., Quinn, E. A., \& Louis, W. R. (2011). Appealing to common humanity increases forgiveness but reduces collective action among victims of historical atrocities. European Journal of Social Psychology, 41, 569-573. doi:10.1002/ejsp.802

Greenwald, A. G., \& Banaji, M. R. (1995). Implicit social cognition: Attitudes, self-esteem, stereotypes. Psychological Review, 102, 4-27. doi:10.1037/0033-295X.102.1.4

Hall, N., \& Crisp, R. J. (2005). Considering multiple criteria for social categorization can reduce intergroup bias. Personality and Social Psychology Bulletin, 31, 1435-1444. doi:10.1177/0146167205276084

Haslam, N. (2006). Dehumanization: An integrative review. Personality and Social Psychology Review, 10, $252-264$. doi:10.1207/s15327957pspr1003

Haslam, N., Bain, P., Douge, L., Lee, M., \& Bastian, P. (2005). More human than you: Attributing humanness to self and others. Journal of Personality and Social Psychology., 89, 937-950. doi:10.1037/0022-3514.89.6.937

Haslam, N., \& Loughnan, S. (2014). Dehumanization and infrahumanization. Annual Review of Psychology, 65, 399423. doi:10.1146/annurev-psych-010213-115045

Haslam, N., Loughnan, S., Kashima, Y., \& Bain, P. (2008). Attributing and denying humanness to others. In W. Stroebe, \& M. Hewstone (Eds.), European review of social psychology (Vol. 19, pp. 55-85). London, UK: Psychology Press. doi:10.1080/10463280801981645

Hayes, A. F. (2015). An index test of linear moderated mediation. Multivariate Behavioral Research, 50, 1-22. doi: $10.1080 / 00273171.2014 .962683$

Hayes, A. F., \& Preacher, K. J. (2014). Statistical mediation analysis with a multicategorical independent variable. British Journal of Mathematical and Statistical Psychology, 67, 451-470. doi:10.1111/bmsp.12028

Hornsey, M. J., \& Hogg, M. A. (2000). Subgroup relations: A comparison of mutual intergroup differentiation and common ingroup identity models of prejudice reduction. Personality and Social Psychology Bulletin, 26, $242-256$. doi: $10.1177 / 0146167200264010$

Kang, S. K., \& Bodenhausen, G. (2014). Multiple identities in social perception and interaction: Challenges and opportunities. Annual Review of Social Psychology, 66, 547-574. doi:10.1146/annualrev-psych-010814-015025

Kemper, T. D. (1987). How many emotions are there? Wedding the social and automatic components. American Journal of Sociology, 93, 263-289. doi:10.1086/228745

Leyens, J. P., Cortes, B., Demoulin, S., Dovidio, J. F., Fiske, S. T., Gaunt, R., ... Vaes, J. (2003). Emotional prejudice, essentialism, and nationalism: The 2002 Tajfel Lecture. European Journal of Social Psychology, 33, 703-717. doi: $10.002 /$ ejsp. 170

Leyens, J. P., Demoulin, S., Vaes, J., Gaunt, R., \& Paladino, M. P. (2007). Infra-humanization: The wall of group differences. Journal of Social Issues and Policy Review, 1, 139-172. doi:10.1111/j.1751-2409.2007.00006.x

Leyens, J. P., Paladino, M. P., Rodríguez, R. T., Vaes, J., Demoulin, S., Rodríguez, A. P., \& Gaunt, R. (2000). The emotional side of prejudice: The role of secondary emotions. Personality and Social Psychology Review, 4, $186-197$. doi:10.1207/S15327957PSPR0402

McFarland, S., Brown, D., \& Webb, M. (2013). Identification with all humanity as a moral concept and psychological construct. Current Directions in Psychological Science, 22, 192-196. doi:10.1177/0963721412471346

McFarland, S., \& Hornsby, W. (2015). An analysis of five measures of global human identification. European Journal of Social Psychology, 45, 806-817. doi:10.1002/ejsp.2161 
Morton, T. A., \& Postmes, T. (2011). Moral duty or moral defence? The effect of perceiving shared humanity with the victims of intergroup harm. European Journal of Social Psychology, 41, 121-134. doi:10.1002/ejsp.751

Prati, F., Crisp, R. J., Meleady, R., \& Rubini, M. (2016). Humanizing outgroups through multiple categorization: The roles of individuation and threat. Personality and Social Psychology Bulletin, 42, 526-539. doi:10.1177/ 0146167216636624

Schmidt, S. (2009). Shall we really do it again? The powerful concept of replication is neglected in the social sciences. Review of General Psychology, 13, 90-100. doi:10.1037/a0015108

Tajfel, H., Billig, M., Bundy, R. F., \& Flament, C. (1971). Social categorization and intergroup behavior. European Journal of Social Psychology, 1, 149-178. doi:10.1002/ejsp.2420010202

Turner, J. C., Hogg, M. A., Oakes, P. J., Reicher, S. D., \& Wetherell, M. S. (1987). Rediscovering the social group: A selfcategorization theory. New York, NY: Basil Blackwell.

Vaes, J., Leyens, J. P., Paladino, M. P., \& Miranda, M. P. (2012). We are human, they are not: Driving forces behind outgroup dehumanisation and the humanisation of the ingroup. In W. Stroebe, \& M. Hewstone (Eds.), European review of social psychology (Vol. 23, pp. 64-126). London, UK: Psychology Press. doi:10.1080/10463283.2012.665250

Waytz, A., Gray, K., Epley, N., \& Wegner, D. (2010). Causes and consequences of mind perception. Trends in Social Cognition, 14, 383-388. doi:10.1016/j.tivs.2010.05.006

Wohl, M. J. A., \& Branscombe, N. R. (2005). Forgiveness and collective guilt assignment to historical perpetrator groups depend on the level of social category inclusiveness. Journal of Personality and Social Psychology, 88, 288303. doi:10.1037/0022-3514.88.2.288 